\title{
Fuel poverty in the UK: Is there a difference between rural and urban areas?
}

\author{
Deborah Roberts ${ }^{\mathrm{a}, \mathrm{c}, *}$, Esperanza Vera-Toscano ${ }^{\mathrm{b}}$, Euan Phimister ${ }^{\mathrm{c}}$ \\ ${ }^{a}$ Social, Economic and Geographical Sciences group, James Hutton Institute, United Kingdom \\ ${ }^{\mathrm{b}}$ Instituto de Estudios Sociales Avanzados (IESA), Consejo Superior de Investigaciones Científicas (CSIC), Córdoba, Spain \\ ${ }^{\mathrm{c}}$ Aberdeen Centre for Research in Energy Economics and Finance, Business School, University of Aberdeen, United Kingdom
}

\section{H I G H L I G H T S}

- Urban fuel poverty is more persistent on average than rural fuel poverty.

- Rural fuel poor are on average more vulnerable to energy price shocks.

- Fuel poverty policy measures may have different effects in rural and urban areas.

- Both spatial and household targeting required for policy effectiveness.

- Policy makers should to consider additional monitoring of dynamics of fuel poverty.

\section{A R T I C L E I N F O}

\section{Article history:}

Received 8 May 2015

Received in revised form

23 August 2015

Accepted 28 August 2015

Available online 24 September 2015

\section{Keywords:}

Fuel poverty

Dynamics

Rural

Urban

Policy

\begin{abstract}
A B S T R A C T
Fuel poverty is a significant policy issue. An argument often made is that rural households are more likely to be fuel poor due to the nature of rural housing stock and the more limited choice of energy sources in rural areas. This paper uses panel data to compare the level and dynamics of fuel poverty in rural and urban areas of the UK. In addition to descriptive analysis, discrete hazard models of fuel poverty exit and re-entry are estimated and used to assess the influence of housing and personal characteristics on the time spent in fuel poverty. The results indicate that, on average, the experience of fuel poverty in urban areas is longer with a higher probability of fuel poverty persistence. However, on average the rural fuel poor appear more vulnerable to energy price increases while living in private accommodation or a flat increases their probability of remaining fuel poor relative to their urban counterparts. These results indicate policy effectiveness may differ across rural and urban space. However, they also emphasise the limits of spatial targeting. Monitoring the dynamics of fuel poverty is important for ensuring that policy targets are effective and reaching those most in need.
\end{abstract}

(c) 2015 Elsevier Ltd. All rights reserved.

\section{Introduction}

An individual is defined as fuel (or energy) poor if they are unable to adequately heat their home through a lack of resources and because of the inefficiency of the housing insulation and heating (Boardman, 1991, 2012; Bouzarovski et al., 2012; Liddell et al., 2012). The concept of fuel poverty is thus multidimensional, depending on household income, the cost of energy and the energy efficiency of an individual's home.

Fuel poverty has several welfare implications. It has been linked to respiratory problems, circulatory problems, pneumonia,

\footnotetext{
* Corresponding author.

E-mail address: deb.roberts@hutton.ac.uk (D. Roberts).
}

adverse effects on mental health and an increase in unintentional injuries (Liddell and Morris, 2010; Public Health England, 2014). It has also been associated with the lower educational attainment of children (Barnes et al., 2008). Over and above these direct impacts, the continuing existence of energy inefficient homes is clearly inconsistent with the longer term global policy agenda of addressing climate change.

The level of fuel poverty in the UK has varied significantly over the last twenty years, declining in the late 1990s and then increasing rapidly from 2003 to 2010, the latter due to the dramatic increase in nominal domestic electricity and gas prices over the same period (75\% and 120\%, respectively, (DECC, 2015)). Official UK statistics show that the level of fuel poverty fell between 2010 and 2011, due to "rising energy efficiency standards (particularly 
among lower income households) and a fall in energy prices". (DECC, 2014a, p. 62), but since then has remained roughly constant and at a level where one in ten UK households remain classified as fuel poor. In this context, it is not surprising that reducing fuel poverty has become a major UK policy target as well as internationally (Bouzarovski et al., 2012).

Understanding movements into and out of fuel poverty, as well as the level of fuel poverty at any point in time, is important because the welfare implications and thus policy measures will be different depending on how such poverty is experienced. For example, if many households experience fuel poverty for a short period of time, the required policy response will be different to that required if a small number of households experience fuel poverty persistently.

Conceptually the need to understanding the dynamic processes underlying low pay has been recognized. Bouzarovski et al. (2014) argue that fuel poverty should be embedded within a wider energy poverty framework focussing on the notion of "energy vulnerability" as it allows a better focus on the pathways through which households are prevented in achieving their energy needs. However, while previous studies have considered the importance of targeting fuel poverty polices either spatially or by housing type (Sefton, 2002; Walker et al. 2012), there has been relatively little attention on the dynamics of fuel poverty of individuals.

Recent evidence does suggest potential regional differences in vulnerability to energy price increases and volatility at the aggregate level (Jones, 2010, Tirado-Herrero and Bouzarovski, 2014). There is also some limited evidence that the individual incidence of fuel poverty varies across rural and urban space (Thomson and Snell, 2013). However, there has been little focus on potential rural-urban differences and why they might arise. This is perhaps surprising given the extensive research considering social deprivation and its experience across space (e.g. Campanera and Higgins, 2011; Cloke et al. 1997; Huby et al., 2009; Phimister et al., 2000). ${ }^{1}$ In the context of fuel poverty, an argument often raised in the policy debate is that rural households are disadvantaged due to the nature of rural housing stock and the more limited choice of energy available in rural areas. $^{2}$

The proportion households off the gas grid varies across the UK with, in 2012, the South West region and Scotland having the highest proportion of properties without a gas meter (20\% and 18\% respectively) (DECC, 2013). Rural areas in particular have a high percentage of households off gas grid due to distance from the gas network (DECC, 2013) and, as a consequence, rural consumers are more likely to use non-mains gas heating fuels. Homes reliant on non-gas heating fuels tend to have lower energy efficiency standards than gas-heated homes with a greater likelihood of such homes being older, detached and built with solid walls, resulting in higher heating costs (Consumer Focus, 2011).

In addition to a more limited choice of heating fuels, there has been public concern in relation to the competitiveness of heating fuel supply and other fuel markets in rural areas due to observed rural-urban price differentials and the way they have changed over time. By definition the limited choice of fuels also means there are structural differences in the relationships between fuel markets across space which affects the nature of potential competition. For example in off gas grid rural areas heating fuel competes with bottled gas, which is not the case for grid connected communities. In 2011 the market for heating oil and other

\footnotetext{
${ }^{1}$ This research emphasises that while UK incomes are on average higher in rural areas, income poverty is substantial, and is often "hidden" in nature, with substantial persistent poverty and fewer labour market opportunities for certain groups.

${ }^{2}$ In contrast to other energy sources, the availability of firewood is likely to be greater in rural areas.
}

"off-grid" forms of energy was investigated by the Office of Fair Trading (OFT). While the investigation found no evidence of a competition problem that would require intervention to regulate prices, the report did note that high concentration is an issue for the supply of many products and services in areas characterised by sparse populations and access issues and highlighted that "there is a proportion of the off-grid community that is particularly vulnerable to high prices both in the short term and the longer term, notably the subset of consumers in deep rural locations with little choice of suppliers, poor housing stock, and low incomes." (Office of Fair Trading, 2011, p. 8). This will affect the ability of rural households to adjust to increasing energy prices and their movements into and out of fuel poverty. This in turn may influence the effectiveness of existing policy mechanisms.

This paper uses data from the most recent twelve waves of the British Household Panel Survey (BHPS) to compare both the level and the dynamics of fuel poverty in rural and urban parts of the UK over the last twenty years. An expenditure-based measure of fuel poverty is constructed and used to explore, first at aggregate level and then at micro-level, rural-urban differences. Particular attention is given to the role of an individual's characteristics, the characteristics of their housing and energy prices in determining fuel poverty persistence and transitions (Jarvis and Jenkins, 1997; Phimister et al., 2000; Stevens, 1999).

The results show that despite the higher probability of being trapped in persistent fuel poverty among urban dwellers, the impact of some of the characteristics already known to adversely influence the level of fuel poverty (living in a flat, and living in private rental accommodation) have an even more negative effect in rural areas than in urban areas. Moreover, they also indicate that an individual from an average rural household is more vulnerable to fuel price increases than an individual from an average urban area. More fundamentally the results suggest monitoring not only changes in the level of fuel poverty but also how fuel poverty is experienced at the individual level is important in order to ensure that policy targets are effective and reaching those most in need.

In Section 2 we discuss alternative ways of identifying those in fuel poverty and justify the particular expenditure-based measure used in the analysis. Section 2 also discusses how hazard modelling is used to explore the source of rural-urban differences in the fuel poverty dynamics. Section 3 presents both descriptive and econometric estimation results and draws out their implications by identifying the sources of rural-urban differences and the vulnerability of different household types to energy price increases. Section 4 concludes and provides a discussion of the key policy implications.

\section{Methods}

\subsection{The measurement of fuel poverty and source of data}

There is no agreement on how best to measure whether an individual is fuel poor. At European level, a ten percent threshold of actual energy expenditure has been widely used (EC, 2010). However, measures of who are fuel poor based on actual expenditure have been criticized as they potentially miss those who, in the face of difficulties in heating their home, respond by reducing energy expenditure (Dubois, 2012). Strategies adopted by such individuals include heating a single room, increasing clothing worn, spending more time in bed or reducing lighting (Brunner et al., 2012). An alternative definition of fuel poverty was developed in the UK to address this using a household's required spending based on the energy efficiency of the home (DoE, 1996). However, within the UK, the way in which fuel poverty is defined now differs across administrations. In Wales, Northern Ireland, and 
Scotland, a household is in fuel poverty if, in order to maintain a satisfactory heating regime, it is required to spend more than $10 \%$ of its income on household fuel use (DSD, 2011; Scottish Government, 2014; Welsh Assembly Government, 2010). In England, a new measure has been introduced based on the Hills' review of Fuel Poverty (Hills, 2012). This defines a household as fuel poor if they have required fuel costs above the median household level and, if they were to spend that amount, live in a household whose income falls below the official poverty line (Hills, 2012). Although the latter captures the dual aspects of fuel poverty arising from poverty and housing energy (in)efficiency, it has been criticized as insensitive to the impact of energy price or climate changes (Moore, 2012).

Alternative subjective fuel and energy poverty measures have also been widely used. These are typically based on responses to questions as to whether an individual's feels their accommodation has adequate heating (see, for example, Healy and Clinch, 2004). Although the subjective nature of the questions mean that their exact relationship to fuel poverty is not always clear-cut, these measures avoid missing households that are "rationing their energy consumption" (Dubois 2012, p. 109). ${ }^{3}$ Research shows that although related, the relationship between expenditure-based and subjective measures is often complex, and that subjective energy poverty measures can be useful in capturing aspects of energy poverty which expenditure-based measures may miss (Waddams Price et al., 2012; Phimister et al., 2015)

In the analysis below we adopt the measure of fuel poverty based on actual expenditure and household income using data from the British Household Panel Survey, with an individual defined as being in fuel poverty if they are living in a household where household energy expenditure is above $10 \%$ of household income. Household energy expenditure is calculated using answers to available questions on the household's annual expenditure on electricity, gas, and heating oil. This value is then equivalized using the scales used in fuel poverty calculations by DECC (2014a, p. 81). To calculate household income value, we construct an annualised net housing cost for each household based on the monthly information available. This is then subtracted from annual net household income (which allows for direct taxes and benefits) (Levy and Jenkins, 2012) to provide an estimate of annual after housing cost net income. Finally, to allow for differences in need across households driven by size, household income is adjusted using the equivalisation factors used by DECC (2014a, p. 82).

The definition used is clearly open to a number of criticisms. Any threshold based on actual energy expenditure may underestimate movements out of and into fuel poverty as it does not capture the impact of household who are "rationing their energy consumption" (Dubois, 2012). Second, although the 10\% threshold used is widely used and is consistent with the past UK wide definition used by policy makers, it is ultimately arbitrary and the incidence and typical characteristics of fuel poverty are often quite sensitive to the threshold and exact fuel poverty definition used (Heindl, 2014). While recognizing its limitations nevertheless the definition adopted should capture rural-urban differences in the experience of fuel poverty if they exist. This is because the impact of rural residents having a more limited range of fuel options will, all other things being equal, be reflected in their response to changes in energy prices. Moreover structural differences in the housing stock in rural areas (e.g. more detached houses, fewer flats) would also be expected to return higher energy expenditure levels. As noted above there were large changes in energy prices

\footnotetext{
${ }^{3}$ Subjective fuel poverty measures are often based on individual answers to multiple questions such as whether their house has leaks or damp, whether their household can afford to keep the dwelling heated warm in the winter and whether any utility bills were paid late recently.
}

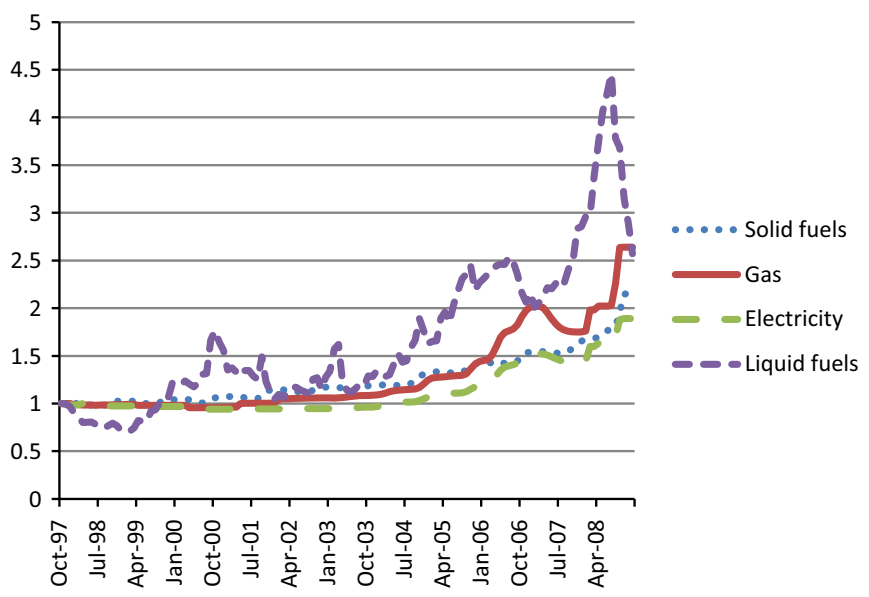

Fig. 1. Changes in fuel prices, 1997-2008. Source: DECC (2014b).

over the period analysed which differed considerably by fuel type (see Fig. 1). Moreover, the impact of the potential sensitivity of the results to the threshold chosen may be less when the focus, as here, is comparative analysis of fuel poverty experience across different samples rather than on fuel poverty incidence. ${ }^{4}$

The analysis below is based on individual data from the last twelve waves of the British Household Panel Survey (BHPS) ${ }^{5}$. This provides repeated information on individuals and households over the period $1997 / 98$ to $2008 / 09$. From this data, an unbalanced panel of individuals who have remained in the sample for at least three years continuously was constructed, excluding those participants recruited in later years, i.e. only those with a longitudinal weight are included.

The rural indicators available in the BHPS vary across the Scottish and England and Wales samples, reflecting the different definitions of rural and urban areas across the UK used by government. However, both can be used to identify individuals living in settlements with fewer than ten thousand inhabitants which is the common element of the rural definitions used by DEFRA (2013) and the Scottish Government (2009). This threshold is used in the analysis to identify whether an individual is defined as being part of the "rural" sample or not. Based on this definition, the overall sample contains 1506 and 4812 individuals classified as rural and urban respectively. Using twelve waves results in 15,144 rural and 46,211 urban observations.

\subsection{Modelling dynamics of fuel poverty}

After providing a descriptive analysis of fuel poverty dynamics in the data, we explore the source of any rural-urban differences and the vulnerability of different household types to energy price increases using hazard models. To undertake this we use the repeated information on individual experiences of fuel poverty to construct a sample of fuel poverty spells. Excluding left censored spells, 1157 rural and 3647 urban spells in fuel poverty were constructed; and 1028 rural and 3124 urban spells out of fuel poverty.

Any observed rural-urban differences in fuel poverty mobility may arise due to differences in the observed and unobserved characteristics of the individuals and households in the two

\footnotetext{
${ }^{4}$ Some testing on the sensitivity of the results to the fuel poverty definition was undertaken with respect to the inclusion or inclusion of housing costs in household income.

${ }^{5}$ Earlier waves were excluded as the nature of the questions asked on household energy expenditure changed substantially in wave 7 (1997/98) but are consistent thereafter.
} 
samples. Alternatively the differences may be due to different behavioural responses of individuals associated with where they live. To capture these possibilities we specify two discrete proportional hazard models. Consider two types of spells $j$ of fuel poverty (or spells out of fuel poverty) where $t$ measures the length or duration of the spell type $j, i$ is the individual. The hazard function $h_{i j}(t)$ can be defined as is the probability that a spell of type $j$ ends between the end of year $t-1$ and $t$ for individual $i$. In formal terms

$h_{i j}(t)=h_{j t 0} \exp \left(\mathbf{x}_{i j} \boldsymbol{\beta}_{j}+\left(d_{i} \mathbf{x}_{i j}\right) \boldsymbol{\delta}_{j}+u_{j}\right)$

where $h_{j t 0}$ is the baseline exit (or re-entry) hazard, $\mathbf{x}_{i j}$ are the observed covariates, ${ }^{6} d_{i}$ is a rural dummy, with $\boldsymbol{\beta}_{j}$ capturing the urban impact of each covariate and $\boldsymbol{\delta}_{j}$ the extent of any ruralurban difference in impact. If fuel poverty mobility is relatively high many individuals are likely to have experienced repeated spells of fuel poverty (and spells out of fuel poverty), where any unobserved individual factors might be correlated. Thus $u_{j}$ captures the unobserved heterogeneity for spell type $j$ where $u_{j}$ are assumed jointly normally distributed across spell types to account for possible correlations between unobserved heterogeneity across states.

The covariates included in the hazard functions reflect observed characteristics which are expected to play a role in fuel poverty exits and re-entry and where their impact might be expected to differ across rural and urban samples. Hence we include information on housing characteristics (whether the residence is a flat or a house and the number of rooms) and tenure type (Healy and Clinch, 2002). Demographic characteristics of the household are also included such as the number of children under 16 , whether the head of household is employed and their level of education. Finally, two potentially time varying factors are used: regional average heating degree days to reflect the average climatic conditions in the year, and energy price (DECC, 2010). The high degree of correlation between the available energy price series (including heating oil and electricity) meant that the separate impact of multiple energy price series could not be identified in the estimations so a single price was used to represent the general movement in energy prices over the period. In this case, the credit sales gas price (deflated by the consumer price index) was chosen as it had the highest correlation with the heating oil price and therefore it was best able to capture the impact of changes in heating energy prices in rural areas without gas grid.

The data was reorganised into a binary format and five individual dummy variables each for exit and re-entry are defined. These capture the baseline hazards for the first four possible exit (re-entry) periods and then for period 5 and above. Within this format the two-state discrete hazard models were then estimated within a multi-level modelling framework applying standard estimation techniques (Rabe-Hesketh and Skrondal, 2012).

\section{Results and discussion}

\subsection{Descriptive analysis}

Table 1 reports the level of fuel poverty in the UK over the period and compares it to the level of income poverty. Income poverty is based on the standard definition of living with $60 \%$ or less of the equivalized medium household income. The numbers of observations are provided in brackets.

The overall level of fuel poverty in rural and urban parts of the

\footnotetext{
${ }^{6}$ Although the $t$ subscript is omitted for brevity, time varying covariates are included in this equation.
}

Table 1

Levels of fuel and income poverty (\%), 1997-2008.

\begin{tabular}{llll}
\hline Given in & \multicolumn{2}{l}{ Also in } & \\
\cline { 2 - 4 } & Fuel poverty & Income poverty & Total \\
\hline Rural & & & \\
Fuel poverty & - & $31.5 \%(869)$ & $18.2 \%(2762)$ \\
$\begin{array}{l}\text { Income poverty } \\
\text { Urban }\end{array}$ & $54.5 \%(869)$ & - & $10.5 \%(1596)$ \\
Fuel poverty & & $33.2 \%(2775)$ & $18.0 \%(8311)$ \\
$\begin{array}{l}\text { Income poverty } \\
\text { Total }\end{array}$ & $47.8 \%(2775)$ & - & $12.0 \%(5537)$ \\
\hline
\end{tabular}

UK is shown to be almost identical at around $18 \%$. Only $31.5 \%$ of rural individuals in fuel poverty are also in income poverty reflecting the fact that the fuel poor includes higher income individuals facing high fuel prices and/or in energy inefficient homes. In comparison, $54.5 \%$ of those rural individuals classified as income poor are also in fuel poverty. This highlights the difficulty of targeting fuel poverty policies in a manner which assists those most in need.

An initial picture of fuel poverty mobility is provided in Table 2 . This reports the average year to year rates of mobility into and out of fuel poverty across the rural and urban samples over the entire period. Mobility levels are high-much higher than those typically observed for movements into and out of income poverty - and again very similar for rural and urban areas. For example, over the period $1997-2008,50.3 \%$ of the rural sample who were in fuel poverty at the beginning of a year had left fuel poverty by the beginning of the next compared to $51.1 \%$ of urban residents. Similarly, of those who were not in fuel poverty at the beginning of a period, $11.0 \%$ of rural residents ( $11.6 \%$ of urban residents) had entered fuel poverty by the beginning of the next.

Fig. 2 indicates the incidence of fuel poverty in each of the waves of data. The pattern follows that expected with an initial fall then increase post 2002 as a result of energy price increases. Interestingly, while the general trends in fuel poverty in rural and urban parts of the UK are similar, there is a statistically significant difference between the two with rural poverty rates first higher and then post 2003/04 lower than those observed in urban areas.

\subsection{Spells in and out of fuel poverty}

As discussed above we construct a sample of fuel poverty spells at the individual level and analyse these by estimating hazard models of fuel poverty exit and re-entry. To explore differences in the underlying data, these were first used to estimate rural and urban survivor functions for spells in fuel poverty (Fig. 3a) and spells out of fuel poverty (Fig. 3b) where the survivor function value for period $t$ is the probability that a spell which has just begun lasts for more than $t$ periods.

For exits out of the fuel poverty, the log rank test suggests that there are statistically significant differences between the rural and

Table 2

Average year to year mobility into (out of) fuel poverty.

\begin{tabular}{lllll}
\hline & \multicolumn{3}{l}{ Year $\boldsymbol{t}+\mathbf{1}$} & \\
\cline { 3 - 5 } & & Not fuel poor & Fuel poor & \multirow{2}{*}{ N } \\
\hline Rural & & & & \\
Year t & Not fuel poor & 89.0 & 11.0 & 10,950 \\
Urban & Fuel poor & 50.3 & 49.7 & 2211 \\
Year t & Not fuel poor & 88.4 & 11.6 & 34,186 \\
& Fuel poor & 51.1 & 48.9 & 6794 \\
\hline
\end{tabular}




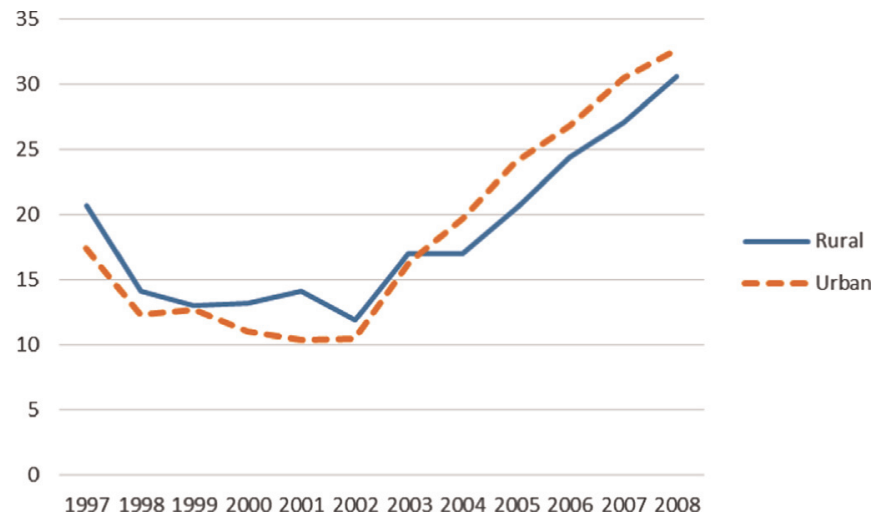

Fig. 2. Changes in fuel poverty rates, 1997-2008.

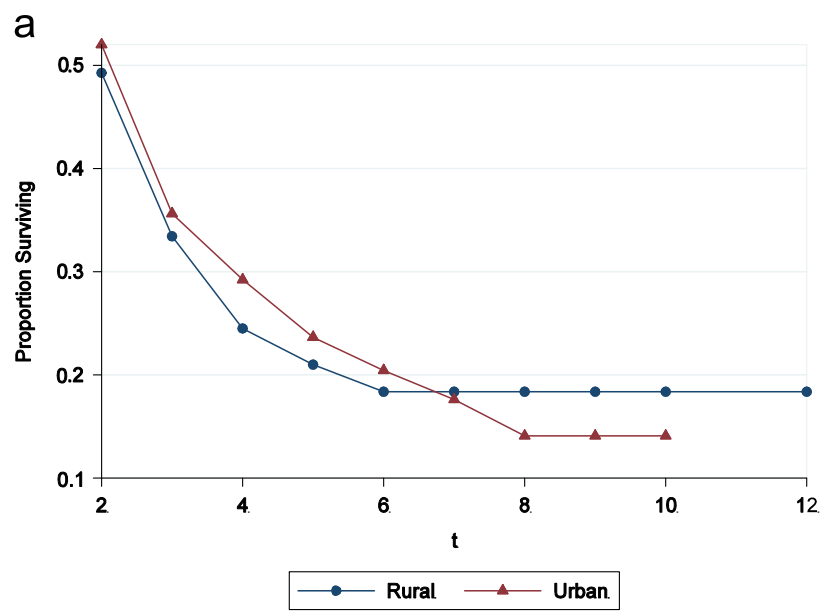

fuel poverty. Although their coefficients are not reported, as discussed above, within each model five individual dummy variables were included to capture the baseline hazard for the first four possible exit (re-entry) periods and then for period 5 and above. These dummy variables are also well determined and are individually and jointly significant at $1 \%$.

In terms of rural-urban differences, the overall joint hypotheses test in the bottom panel of Table 3 that all rural and urban coefficients are equal suggests that the impact of the covariates do differ for the rural sample $(p$-value $=0.019)$. Consistent with the survivor function results, the source of these rural-urban differences appears to arise from differences in the dynamics of exit from fuel poverty, with the joint test that all rural and urban exit coefficients are equal rejected ( $p$-value $=0.014$ ). In contrast, the joint test that all rural and urban re-entry coefficients are equal is not rejected at the $10 \%$ significance level.

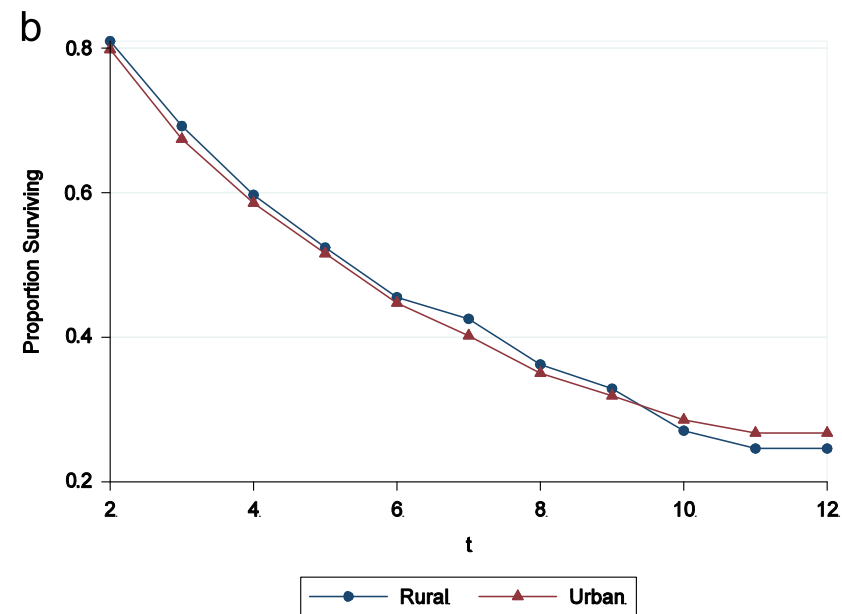

Fig. 3. Survival Function Exits out of and Re-entry into Fuel poverty.

urban survivor functions at $1 \%(p$-value $=0.005)$. Here, survivor rates are initially lower for the rural sample than the urban one although there is a cross over indicating that the probability that a fuel poverty spell lasts longer than 7 periods is higher for the rural sample. Hence, a rural resident who has just entered a spell of fuel poverty is more likely to exit this state in the first seven years but is less likely to exit should the spell last longer than this. In contrast, for periods out of fuel poverty the evidence that the dynamics of re-entry into fuel poverty differ across the two samples is much weaker, with the null hypothesis that the survivor functions differ not rejected at $10 \%(p \text {-value }=0.13)^{7}$

\subsection{Results from the hazard models}

Table 3 reports the estimation results from the hazard models, presenting the marginal effects for each covariate and the interaction with the rural dummy. The model fitted has reasonable explanatory power overall with a number of variables individually statistically significant. From the second panel (below the estimated coefficients) the unobserved heterogeneity is significant in both states and, as expected, these effects are negatively correlated. That is, an individual with an unobserved effect which increases the exit hazard from fuel poverty is more likely to have unobserved effect which decreases the re-entry hazard back into

\footnotetext{
7 There is some evidence that this result is sensitive to the definition of fuel poverty. In particular, where the numerator for the $10 \%$ threshold is defined using net household income before housing cost it is found that the null hypothesis that re-entry survivor functions differ is rejected at $5 \%$.
}

The signs on the majority of the individual coefficients are as expected. For example, being in a household with an older head, or being in private rented accommodation (relative to owner occupancy) decreases the probability of a fuel poverty exit. Similarly increases in energy prices (as captured by the representative real gas price) and in heating degree days also reduce the probability of a fuel poverty exit. Although there are fewer individual coefficients which are significant in the re-entry equation, residing in a flat reduces the probability of a return to fuel poverty while residing in a house with more rooms, having more children or being in private rented accommodation increases the probability. In contrast, the impact of the head of household being employed is statistically significant but has the opposite effect to that expected for re-entry and neither the energy price nor the heating degree days are significant.

Importantly, there is evidence of individual rural-urban differences. Consistent with claim that rural residents have less flexibility due to nature of their housing (see introductory section), the impact of being in a flat, in private rented accommodation and the number of children all have a more negative effect for rural residents in the exit model. In particular, after controlling for other factors, an increase in energy price significantly reduces the likelihood of an urban household exiting fuel poverty but has an even greater negative impact on a rural household's exit probability. As one might expect given the overall joint hypothesis test result, there are few individually significant rural-urban differences for re-entry to fuel poverty, although notably the impact of having an older head of household increases the probability of re-entry for the rural sample while heating degree days is more negative in the 
Table 3

Discrete hazard model: covariate marginal effects fuel poverty exit and re-entry.

\begin{tabular}{|c|c|c|c|c|}
\hline & \multicolumn{2}{|l|}{ Exits } & \multicolumn{2}{|l|}{ Re-entry } \\
\hline & Urban & $\begin{array}{l}\text { Rural-urban } \\
\text { difference }\end{array}$ & Urban & $\begin{array}{l}\text { Rural-urban } \\
\text { difference }\end{array}$ \\
\hline Rural & & $\begin{array}{l}1.088 \\
(0.734)\end{array}$ & & $\begin{array}{l}0.715 \\
(0.735)\end{array}$ \\
\hline Flat & $\begin{array}{l}0.090 \\
(0.099)\end{array}$ & $\begin{array}{l}-0.499+ \\
(0.268)\end{array}$ & $\begin{array}{l}-0.198+ \\
(0.104)\end{array}$ & $\begin{array}{l}0.335 \\
(0.292)\end{array}$ \\
\hline No. rooms & $\begin{array}{l}-0.047+ \\
(0.024)\end{array}$ & $\begin{array}{l}0.030 \\
(0.047)\end{array}$ & $\begin{array}{l}0.045+ \\
(0.027)\end{array}$ & $\begin{array}{l}0.011 \\
(0.050)\end{array}$ \\
\hline No. children & $\begin{array}{l}0.093 * \\
(0.034)\end{array}$ & $\begin{array}{l}-0.115+ \\
(0.069)\end{array}$ & $\begin{array}{l}0.057+ \\
(0.033)\end{array}$ & $\begin{array}{l}0.062 \\
(0.067)\end{array}$ \\
\hline Head65plus & $\begin{array}{l}-0.240^{*} \\
(0.073)\end{array}$ & $\begin{array}{l}-0.245 \\
(0.150)\end{array}$ & $\begin{array}{l}0.089 \\
(0.078)\end{array}$ & $\begin{array}{l}0.299+ \\
(0.149)\end{array}$ \\
\hline HeadEmployed & $\begin{array}{l}-0.240^{*} \\
(0.093)\end{array}$ & $\begin{array}{l}0.169 \\
(0.170)\end{array}$ & $\begin{array}{l}0.379^{*} \\
(0.097)\end{array}$ & $\begin{array}{l}-0.063 \\
(0.171)\end{array}$ \\
\hline A level plus & $\begin{array}{l}0.059 \\
(0.098)\end{array}$ & $\begin{array}{l}0.028 \\
(0.201)\end{array}$ & $\begin{array}{l}0.039 \\
(0.106)\end{array}$ & $\begin{array}{l}-0.096 \\
(0.210)\end{array}$ \\
\hline Public rented & $\begin{array}{l}0.081 \\
(0.090)\end{array}$ & $\begin{array}{c}-0.016 \\
(0.207)\end{array}$ & $\begin{array}{l}-0.009 \\
(0.087)\end{array}$ & $\begin{array}{l}0.070 \\
(0.189)\end{array}$ \\
\hline Private rented & $\begin{array}{l}-0.195^{*} \\
(0.097)\end{array}$ & $\begin{array}{l}-0.421^{*} \\
(0.204)\end{array}$ & $\begin{array}{l}0.412^{*} \\
(0.109)\end{array}$ & $\begin{array}{l}-0.038 \\
(0.213)\end{array}$ \\
\hline Gas price & $\begin{array}{l}-1.444^{*} \\
(0.074)\end{array}$ & $\begin{array}{c}-0.169 \\
(0.144)\end{array}$ & $\begin{array}{c}-0.028 \\
(0.070)\end{array}$ & $\begin{array}{l}0.049 \\
(0.137)\end{array}$ \\
\hline Heat. degree days & $\begin{array}{l}-0.560^{*} \\
(0.103)\end{array}$ & $\begin{array}{l}-0.213 \\
(0.208)\end{array}$ & $\begin{array}{l}-0.004 \\
(0.107)\end{array}$ & $\begin{array}{l}-0.416+ \\
(0.212)\end{array}$ \\
\hline $\operatorname{Var}(\operatorname{InEP})$ & $\begin{array}{l}0.147 \\
(0.065)\end{array}$ & Var(OutofEP) & $\begin{array}{l}0.390 \\
(0.098)\end{array}$ & \\
\hline $\operatorname{Cov}($ In,OutofEP) & $\begin{array}{l}-0.240 \\
(0.064)\end{array}$ & & & \\
\hline Log Likelihood & -11058.7 & $\begin{array}{l}\text { Total No } \\
\text { Spells }\end{array}$ & 4051 & \\
\hline Hypothesis Tests & Overall & $\begin{array}{l}\text { Rural-urban } \\
\text { Diffs.: All }\end{array}$ & $\begin{array}{l}\text { Rural-urban } \\
\text { Diffs: Exits }\end{array}$ & $\begin{array}{l}\text { Rural-urban } \\
\text { Diffs.: Re- } \\
\text { entry }\end{array}$ \\
\hline Chi-squared (d.f.) & $4731.79(52)$ & $37.69(22)$ & $23.8(11)$ & $15.0(11)$ \\
\hline p-value & $<0.001$ & 0.019 & 0.014 & 0.189 \\
\hline
\end{tabular}

Estimation includes 5 dummy variables to capture the exit baseline hazards which are common across the urban and rural sample and 5 dummy variables to capture re-entry baseline hazards, which are similarly common across the two samples. Standard Errors in brackets.

* + Coefficient Significant at 5\%, 10\% level respectively.

rural sample which is not consistent with expectations.

\subsection{Repeated Spells analysis}

The results from the hazard models can be used to determine whether differences in the experience of fuel poverty between rural and urban residents is due to differences in the average characteristics of the two samples or differences in the impact of the covariates on the exit and re-entry into fuel poverty. Given the high rates of mobility between the two states over time, the focus is on repeated spells in fuel poverty. In particular, the analysis uses the estimation results from Table 3 to simulate all possible low fuel poverty spells over a six year period given that the individual has just fallen into fuel poverty (Jenkins and Rigg, 2001; Stevens, 1999). In this analysis, random effects are assumed to be zero.

As shown in Table 4, a rural resident with average characteristics who has just fallen into fuel poverty would be expected to spend an average of 3.45 years in fuel poverty over the next six years. The probability of spending one period in fuel poverty is 0.223 while the probability that he or she spends five or more periods in fuel poverty is $0.347(0.109+0.238)$. The second row provides comparable results for the urban sample using the urban estimated coefficients. In this case both the expected time spent in fuel poverty (3.57) and the probability of spending five or more in fuel poverty is higher (0.374) suggesting that, on average, the
Table 4

Predicted number years in fuel poverty next six years.

\begin{tabular}{|c|c|c|c|c|c|c|c|}
\hline & \multicolumn{7}{|c|}{ Number of years } \\
\hline & 1 & 2 & 3 & 4 & 5 & 6 & $\begin{array}{l}\text { Expected } \\
\text { Time }\end{array}$ \\
\hline Rural & 0.223 & 0.164 & 0.134 & 0.132 & 0.109 & 0.238 & 3.45 \\
\hline Urban & 0.206 & 0.157 & 0.131 & 0.132 & 0.113 & 0.261 & 3.57 \\
\hline $\begin{array}{l}\text { Rural (urban } \\
\text { coefficients) }\end{array}$ & 0.198 & 0.155 & 0.132 & 0.135 & 0.117 & 0.264 & 3.61 \\
\hline
\end{tabular}

experience of fuel poverty in urban places is somewhat longer with a higher probability of fuel poverty persistence.

To provide an indication of the effects of covariates relative to sample average characteristics, the final row of Table 4 provides predictions of what a rural individual (with average characteristics) falling into fuel poverty might experience if the impact of the covariates was identical to the urban estimates. In this case the average time spent in fuel poverty and fuel poverty persistence increases beyond the urban values suggesting that the rural-urban differences in the coefficients are not only statistically significant (as shown in Table 3) but they also have economic significance in that they affect fuel poverty outcomes.

To assess the vulnerability of different types of households to energy price shocks we undertake the following exercise. First, we calculate the predicted pattern of fuel poverty with the energy price at its mean value in three scenarios: (1) For average urban and rural characteristics; (2) For Household Type 1 defined as that with an employed individual of working age with three children, living in a flat in the public rental sector; and (3) For Household Type 2 defined as a retired pensioner with no children living in a house in the private rental sector. Following this, identical simulations are carried out but when the energy price is increased by $20 \%$. The results are reported in Table 5 .

The top panel of results in Table 5 show that an individual with average rural sample characteristics is more vulnerable to energy price shocks than an average urban resident, with both the overall expected time spent in fuel poverty and the probability of persistent fuel poverty increasing more as a result of the $20 \%$ increase in energy price. The increase in probability of spending 5 or more years in fuel poverty is particularly striking, rising from $35 \%$ to $58 \%$, with the absolute values becoming very similar following the price rise.

The key finding from the second and third panels of results in Table 5 is the extent to which the experience of fuel poverty and impact of price increases depends on household type. Urban residents of both household type 1 and 2 appear more vulnerable to the price increase with a slightly greater percentage increases in overall expected time in poverty and a substantially higher percentage increase in the probability of being in persistent poverty (71\% and 39\% against 52\% and 30\%). This suggests that, while recognising that differences in rural and urban fuel poverty dynamics exist, targeting policy instruments on "average" rural and urban household types would miss critical differences in the vulnerability of households within each area.

\section{Conclusions and policy implications}

There is growing recognition and political sensitivity to the adverse welfare impacts of fuel poverty. These include impacts to physical and mental health, impacts on educational attainments and, for future generations, impacts on climate change. The UK government has recently set new targets for tackling fuel poverty (DECC, 2014a) and each of the UK administrations has a range of 
Table 5

Predicted number years in fuel poverty next six years.

\begin{tabular}{|c|c|c|c|c|}
\hline & Probability of five or more years & \% Change & Overall expected time & $\%$ Change \\
\hline \multicolumn{5}{|l|}{ Average characteristics } \\
\hline Rural average base & 0.35 & & 3.45 & \\
\hline Rural average $+20 \%$ energy price & 0.58 & 66.1 & 4.37 & 26.5 \\
\hline Urban average base & 0.37 & & 3.57 & \\
\hline Urban average $+20 \%$ energy price & 0.58 & 54.9 & 4.38 & 22.7 \\
\hline \multicolumn{5}{|l|}{ Individual in household type 1} \\
\hline Rural type 1 coefficients & 0.41 & & 3.80 & \\
\hline Rural type $1+20 \%$ energy price & 0.62 & 51.8 & 4.59 & 20.7 \\
\hline Urban type 1 coefficients & 0.27 & & 3.20 & \\
\hline Urban type $1+20 \%$ energy price & 0.46 & 71.3 & 3.94 & 23.4 \\
\hline \multicolumn{5}{|l|}{ Individual in household type 2} \\
\hline Rural type 2 coefficients & 0.58 & & 4.45 & \\
\hline Rural type $2+20 \%$ energy price & 0.76 & 29.7 & 5.10 & 14.6 \\
\hline Urban type 2 coefficients & 0.47 & & 4.02 & \\
\hline Urban type $2+20 \%$ energy price & 0.65 & 38.7 & 4.70 & 17.0 \\
\hline
\end{tabular}

policy mechanisms in place targeted at those households considered as most vulnerable. In this way it mirrors an increasing emphasis being given to fuel poverty across the EU (EC, 2010).

Rural residents are often argued to be of particular disadvantage in terms of fuel poverty due to a lack of access to certain fuel types and inefficient housing stock. This paper has explored whether there is evidence of such disadvantage in the UK context, focussing on not only the level of fuel poverty but also whether movements into and out of fuel poverty differ according to where an individual lives. Analysis was based on data from twelve waves of the BHPS covering the period 1997-2008. In addition to descriptive analysis of the panel data, two discrete hazard models of fuel poverty exit and re-entry were estimated allowing for both observed and unobserved heterogeneity of individuals. The observed characteristics controlled for included the nature of housing (owner-occupier versus rented accommodation and house type), personal characteristics (gender, age or education level), differences in energy prices, and differences in temperature across time and space.

At an aggregate level, rates of fuel poverty appear very similar in both areas. However there were statistically significant differences in the survival functions for rural and urban residents for exits from fuel poverty over the period. In particular, a rural resident who has just entered a spell of fuel poverty was found to be more likely to exit this state in the first few years than an urban resident.

The results from the hazard functions indicate that the impact of certain housing and personal characteristics differs across rural and urban space. In particular living in private rental accommodation, living in a flat and having more children are more important determinants of fuel poverty in rural areas than urban areas. The finding that living in private rental accommodation has a more negative effect in rural areas than in urban areas may be associated with the more transient and thinner nature of the private rental market in rural areas which means landlords have less incentive to improve the energy efficiency of their properties.

The results from the hazard functions were used to explore the differences in the duration of fuel poverty in rural and urban areas having allowed for repeated spells. After accounting for differences in the observed characteristics across the two subsamples, the experience of urban fuel poverty was found to be, on average, longer with urban residents having a higher probability of fuel poverty persistence. Further, the results were also used to explore the impact of energy price increases on fuel poverty. A rural individual living in an "average" rural household was found to be more vulnerable to energy price increases than an individual in an average urban household. In particular, a 20\% increase in energy price was estimated to lead to a $66 \%$ increase in the probability of a rural individual being trapped in fuel poverty for five or more years. This is consistent with the argument that rural residents particularly those off the gas grid, are more constrained in their choice of heating and fuel suppliers and also that off gas housing tends to be less energy efficient. However the impact of the price increase varied considerably across households with different combinations of characteristics, confirming that targeting policy instruments on "average" rural and urban household types would miss critical differences in the vulnerability of households within each area.

From a policy perspective, there are four key messages from the analysis. First, they suggest the same policy mechanisms may have different effectiveness in rural and urban areas due to the differential impact of certain factors across space. Second, they suggests that extra attention needs to be paid to fuel poverty in rural areas in periods of rapidly rising energy prices since they are most vulnerable in such periods. Third, the results confirm the importance of particular combinations of household characteristics in determining the likelihood of being in fuel poverty: spatial targeting alone is not likely to be an effective means of targeting polices. They are thus consistent with the shift in all four of the UK administrations towards strategies which target those most fuel poor (measured in the England by the so-called fuel poverty gap) and those most vulnerable to the adverse effects of fuel poverty (households including the old, young, and long term disabled). It also suggests that monitoring not only the levels of fuel poverty but also the dynamics of fuel poverty is important in order to be able to ensure the effectiveness of policy mechanisms.

Given the broader policy interest within the EU in fuel poverty, the analysis applied here could be usefully applied to similar micro panel data available in other EU countries. We would expect different results across countries not least because the way rural areas are defined by national policy makers differs across countries. Cross-country comparative analysis might also be useful in examining the extent to which different national policies, e.g. market liberalisation in the UK, have differentially affected rural and urban consumers by inhibiting (or promoting) the development of gas distribution networks.

\section{Acknowledgements}

Deborah Roberts acknowledges the support of funding from the Scottish Government's Rural and Environment Science and Analytical Services Division (RESAS). We would like to thank the 
reviewers and editor for their valuable comments. All usual caveats apply.

\section{References}

Barnes, M., Butt, S., Tomaszewski, W., 2008. The Dynamics of Bad Housing: The Impact of Bad Housing on the Living Standards of Children. The NatCen Study, National Centre for Social Research, London.

Boardman, B., 1991. Fuel Poverty: From Cold Homes to Affordable Warmth. Belhaven Press, London.

Boardman, B., 2012. Fuel poverty synthesis: lessons learnt, actions needed. Energy Policy 49, 143-148.

Bouzarovski, S., Petrova, S., Sarlamanov, R., 2012. Energy poverty policies in the EU: a critical perspective. Energy Policy 49, 76-82.

Bouzarovski, S., Petrova, S., Tirado-Herrero, S., 2014. From Fuel Poverty to Energy Vulnerability: The importance of Services, Needs and Practices SPRU Working Paper Series December 2014 University of Sussex.

Brunner, K.M., Spitzer, M., Christanell, A., 2012. Experiencing fuel poverty. Coping strategies of low income households in Vienna/Austria. Energy Policy 49, 53-59.

Campanera, J.M., Higgins, P., 2011. Quality of life in urban-classified and ruralclassified English local authority areas. Environ. and Plan. A 43, 683-702.

Cloke, P., Milbourne, P., Thomas, C., 1997. Living lives in different ways? Deprivation, marginalization and changing lifestyles in rural England. Trans. Inst. Br. Geogr. 22, 210-230.

Consumer Focus, 2011. Off-gas consumers Information on households without mains gas heating. William Baker, September 2011 (additional data tables added April 2013). 〈http://www.consumerfocus.org.uk/files/2011/10/Off-gas-con sumers.pdf $\rangle$.

DoE, 1996. English House Condition Survey 1991: Energy Report. Department of the Environment, London, pp. 129-137.

DSD, 2011. Warmer Healthier Homes A New Fuel Poverty Strategy for Northern Ireland. Department for Social Development, Northern Ireland.

DECC, 2010. Domestic Energy Prices: Data Sources and Methodology. Department of Energy and Climate Change, HMSO, London.

DECC, 2013. Areas and types of properties off the gas grid. Special feature - NEED analysis. Department of Energy and Climate Change, HMSO, London.

DECC, 2014a. Annual Fuel Poverty Statistics Report, 2014. Department of Energy and Climate Change, HMSO, London.

DECC, 2014b. Domestic Energy Price Indices, 2014. Department of Energy and Climate Change, HMSO, London.

DECC, 2015. Annual Domestic Energy Bills 2015. Department of Energy and Climate Change, HMSO, London.

DEFRA, 2013. The 2011 Rural-Urban Classification for Small Area Geographies: A User Guide and Frequently Asked Questions (v1.0). Government Statistical Service, London.

Dubois, U., 2012. From targeting to implementation: the role of identification of fuel poor households. Energy Policy 49, 107-115.

EC, 2010. An Energy policy for Customers. Commission Staff Working Paper. European Commission, 11.11.2010. Brussels.

Hills, J., 2012. Getting the Measure of Fuel Poverty, Final Report of the Fuel Poverty Review CASE report 72.

Healy, J.D., Clinch, J.P., 2002. Fuel poverty in Europe: a cross-country analysis using a new composite measure. Working Paper Environmental Studies Research Series, University College Dublin.

Healy, J.D., Clinch, J.P., 2004. Quantifying the severity of fuel poverty, its relationship with poor housing and reasons for non-investment in energysaving measures in Ireland. Energy Policy 32, 207-220.

Heindl, P., 2014. Measuring fuel poverty: general considerations and application to German data. SOEP Papers on Multidisciplinary Panel Data Research 632, Berlin.

Huby, M., Cinderby, S., White, P., de Bruin, A., 2009. Measuring inequality in rural England: the effects of changing spatial resolution. Environ. Plan. A 41, 3023-3037.

Jarvis, S., Jenkins, S.P., 1997. Low income dynamics in 1990s Britain. Fisc. Stud. 18, $123-142$.

Jenkins, S.P., Rigg, J., 2001. The Dynamics of Poverty in Britain. Department of Work and Pensions, HMSO, Research Report No 157.

Jones, C., 2010. Less and less favoured? Britain's regions in the energy crunch. Environ. Plan. A 42, 3006-3022.

Levy, H., Jenkins, S.P., 2012. Documentation for Derived Current and Annual Net Household Income Variables, BHPS waves 1-18. Institute for Social and Economic Research, University of Essex, Colchester, March 2012, UK Data Archive Study Number 3909.

Liddell, C., Morris, C., 2010. Fuel poverty and human health: a review of recent evidence. Energy Policy 38, 2987-2997.

Liddell, C., Morris, C., McKenzie, S.J.P., Rae, G., 2012. Measuring and monitoring fuel poverty in the UK: national and regional perspectives. Energy Policy 38, 27-32.

Moore, R., 2012. Definitions of fuel poverty: implications for policy. Energy Policy 49, 19-26.

Office of Fair Trading, 2011. Off-Grid Energy: An OFT market study. HMSO, London, October 2011. OFT1380.

Phimister, E., Upward, R., Vera-Toscano, E., 2000. The dynamics of low incomes in rural areas. Reg. Stud. 34 (5), 407-417.

Phimister, E., Vera-Toscano, E., Roberts, D., 2015. The dynamics of energy poverty: evidence from spain. Econ. Energy Environ. Policy 4, 153-166.

Public Health England, 2014. Local action on health inequalities: fuel poverty and cold home-related health problems. Health Equity Evidence Review 7: September 2014.

Rabe-Hesketh, S., Skrondal, A., 2012. Multilevel and Longitudinal Modeling Using Stata. Stata Press, Texas.

Scottish Government, 2009. Use and Understanding of the Scottish Government Urban Rural Classification. Scottish Government, Edinburgh, August 2009.

Scottish Government, 2014. Progress Report on the Scottish Fuel Poverty Statement 2002. December 2014. 〈http://www.gov.scot/Resource/0046/00468801.pdf〉.

Sefton, T., 2002. Targeting fuel poverty in England: is the government getting warm? Fisc. Stud. 23, 369-399.

Stevens, A., 1999. Climbing out of poverty. Falling back in: measuring the persistence of poverty over multiple spells. J. Hum. Res. 3, 557-588.

Tirado-Herrero, S., Bouzarovski, S., 2014. Energy transitions and regional inequalities in energy poverty trends: exploring the eu energy divide conference paper. United States Association for Energy Economics (USAEE) Research Paper Series, Working Paper 14-193.

Thomson, H., Snell, C., 2013. Quantifying the prevalence of fuel poverty across the European Union. Energy Policy 52, 563-572.

Price, C. Waddams, Brazier, K., Wang, W., 2012. Objective and subjective measures of fuel poverty. Energy Policy 49, 33-39.

Walker, R., McKenzie, P., Liddell, C., Morris, C., 2012. Area-based targeting of fuel poverty in Northern Ireland: an evidenced-based approach. Appl. Geogr. 2012 (34), 639-649.

Welsh Assembly Government, 2010. Fuel Poverty Strategy 2010. Welsh Government. 〈http://gov.wales/docs/desh/publications/100723fuelpovertystrategyen. pdf $\rangle$. 